Journal of the Magnetics Society of Japan Vol. 15 Supplement, No. S2 (1991)

(c) 1991 by The Magnetics Society of Japan

\title{
EVALUATION OF INCLINATION OF MAGNETIZATION ON A LONGITUDINALLY RECORDED TAPE BY THE BITTER PATTERN TECHNIQUE
}

\author{
Tomoaki SAKURAI*, Osamu KITAKAMI** and Kimiyoshi GOTO ${ }^{*-*}$
}

\begin{abstract}
*Research Institute for Scientific Measurements, Tohoku University, 2-1-1 Katahira, Aoba-ku, Sendai 980, Japan

**Tsukuba Research Laboratory, Hitachi Maxell, Ltd., 6139-1 Onogo, Mitsukaido-shi, Ibaraki 300-25, Japan

***Research Institute for Scientific Measurements, Tohoku University, 2-1-1 Katahira, Aoba-ku, Sendai 980, Japan. Present address: Department of Basic Technology, Faculty of Engineering, Yamagata University, 4-3-16 Jonan, Yonezawa-shi, Yamagata 992, Japan
\end{abstract}

Abstract... To evaluate the inclination of recorded magnetization, the Bitter pattern technique has been applied to a longitudinally recorded VTR tape consisted of acicular Fe particles. The contrast of Bitter patterns evolved in an external magnetic field of $200 \mathrm{Oe}$ with various orientations is observed for 0.5 and $1.0 \mathrm{kFCI}$ recordings, and the inclination angle is found to be $0^{\circ}$ and $180^{\circ}$ for both recordings, as expected. Alternate appearence of dark magnetic transition line is observed when the angle of the magnetic field is larger than $30^{\circ}$ for both recordings, and this agrees well with the calculation of deposited colloid density on the tape. Changes of the contrast of patterns with the angle of magnetic field are also compared with the calculation.

\section{INTRODUCTION}

Most efforts in the field of recent magnetic recording have been devoted to develop the high density recording. Currently three types of recording method, that is, the longitudinal, perpendicular and oblique recordings are being studied to achieve high performance. In these techniques, it is important to make clear the actual orientations of magnetization in recorded bits to improve the recording characteristics. However, we have no suitable magnetic method to measure the inclination of recorded magnetization at present, because the volume of each recorded bit is too small. The present authors [1] applied a modified Bitter pattern technique (the colloid-SEM method [2]) to observe the recorded state of each bit of the perpendicular magnetic recording. Recently, a few theoretical and experimental studies $[3,4]$ have been made for the evolution of the Bitter patterns in a magnetic field. Based on these studies, Kitakami [5] proposed a theory to estimate the inclination of recorded magnetization from the contrast of the Bitter patterns. This theory was derived from the thermodynamic equilibrium evolution of ferrofluid particles. Following the theory, we [6] studied the Bitter patterns on an obliquely metal-evaporated tape of Co-Ni-O alloy, and a value of $40^{\circ}$ was obtained as the inclination of magnetization. In the present study, a 
further experiment is applied to a VTR tape of $\mathrm{Fe}$ powders, where longitudinal signals were recorded, and the inclination of magnetization is evaluated.

\section{EXPERIMENTAL}

Samples used were taken from the high-band $8 \mathrm{~mm}$ VTR tape made of acicular Fe particles (MP tape), which were reduced from $\alpha-\mathrm{FeOOH}$ and which size was roughly 0.16 $\mu \mathrm{m}$ long and $0.016 \mu \mathrm{m}$ in diameter. These particles were coated on a substrate of polyethylene terephthalate up to $2 \mu \mathrm{m}$ in thickness in a longitudinal magnetic field. An iron oxide layer $2.5 \sim 3.0 \mathrm{~nm}$ thick with the spinel structure was detected on the surface of the tape. Magnetic properties of the tape are listed in Table 1. Digital signals of 0.5 and $1.0 \mathrm{kFCI}$ were recorded by a ring head of the metal-in-gap type, whose track width and gap length were $18 \mu \mathrm{m}$ and $0.2 \mu \mathrm{m}$, respectively. To evolve the Bitter patterns, a magnetic colloid [7] was dropped on the surface of the sample in a magnetic field $\mathrm{H}_{\text {ox }}=200 \mathrm{Oe}$ with various angles $\theta$, and the pattern contrast was examined by an optical microscope. The experimental details are the same as the previous paper [6]. The sample setting is shown in Fig.1. In the present study, the recorded magnetization $M_{0}$ is expected to be parallel to the sample surface from the process of the sample preparation; that is, the inclination angle $\phi$ will be zero.

\section{RESULTS AND DISCUSSION}

\section{$0.5 \mathrm{kFCI}$ Recording}

Figure 2 is the preliminary Bitter patterns of the $0.5 \mathrm{kFCI}$ recording taken by the wet pattern method on the same area of the sample. Figure 2(a) and (b) is taken with $\mathrm{H}_{o x}=200 \mathrm{Oe}$ at $\theta=90^{\circ}$ in 2(a) and $\theta=270^{\circ}$ in 2(b). Dark and short lines running vertically are the magnetic transition lines located at $x / b=1$,

Table 1 Magnetic properties of the sample and parameters used in the calculation of the surface density of colloid particles.

\begin{tabular}{|c|c|c|}
\hline Saturation magnetization, & Ms & $220 \mathrm{G}$ \\
\hline Recorded magnetization, & $\mathrm{Mo}_{\mathbf{0}}$ & $180 \mathrm{G}$ \\
\hline Intrinsic coercive force & $\mathbf{m H}_{\mathbf{c}}$ & $1600 \mathrm{Oe}$ \\
\hline Bit length & b & $\begin{array}{r}50.8 \mu \mathrm{m} \\
(0.5 \mathrm{kFCl}) \\
25.4 \mu \mathrm{m} \\
(1.0 \mathrm{kFCl})\end{array}$ \\
\hline \multicolumn{3}{|c|}{ Inclination angle of recorded } \\
\hline magnetization $\mathrm{M}_{\mathrm{o}}$, & $\phi$ & $0^{\circ}$ \\
\hline Thickness of magnetic la & & $2 \mu \mathrm{m}$ \\
\hline $\begin{array}{l}\text { Recorded depth, } \\
\text { Minimum distance from }\end{array}$ & $\delta$ & $0.5 \mu \mathrm{m}$ \\
\hline $\begin{array}{c}\text { the surface, } \\
\text { Maximum distance from }\end{array}$ & yo & $0.1 \mu \mathrm{m}$ \\
\hline the surface, & $y_{1}$ & $1.0 \mu \mathrm{m}$ \\
\hline
\end{tabular}

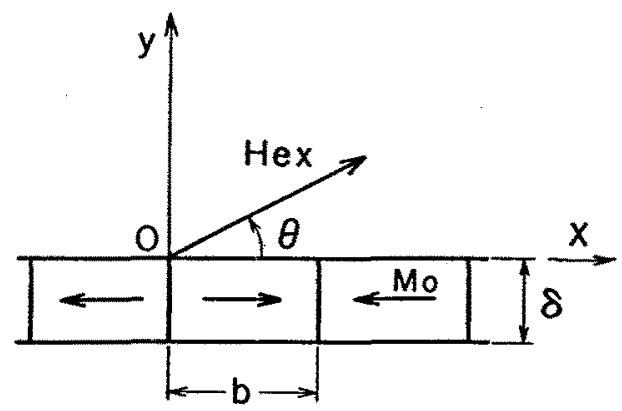

Fig. 1 Sample setting to evolve the Bitter pattern in the external magnetic field. 
2, $3 \cdots$, where $x$ and $b$ are defined in Fig.1. On these magnetic transition lines, colloid particles are deposited preferentially by the large gradient of magnetic field. As seen in these two photos, there is no difference in the colloid density (no contrast) between the bits. Figure 3 shows further examinations of the patterns for neighboring two bits, made by the dry pattern method with $\mathrm{H}_{\text {ox }}=200 \mathrm{Oe}$ of various directions. When $\theta<90^{\circ}$, the colloid density of the right-hand bit is larger than that of the left-hand one, as shown in Fig.3 (a) (c). When $\theta>90^{\circ}$, the left-hand bit becomes darker than the right-hand bit, as shown in (e) and (f), even though some irregularities in the colloid density are observed. In Fig.3 (d) at $\theta=90^{\circ}$, the colloid densities in two bits are nearly equal, as observed in Fig.2 (a) for $\theta=90^{\circ}$.

By the previous calculation [5], the equal density of the colloid particles (the symmetric contrast) for the neighboring bits is obtained when

$$
\cos (\theta+\phi)=0,
$$

where $\phi$ is the inclination angle of $M_{0}$ to the surface. This means that $\theta+\phi=90^{\circ}$ and $270^{\circ}$. At $\theta^{\circ}=90^{\circ}$ (Figs.2 (a) and 3 (d)) and $\theta=270^{\circ}$ (Fig.2(b)), we obtain

$$
\phi=0^{\circ} \text { and } 180^{\circ} \text {. }
$$

These values are expected from the preparation process of the sample.

In Fig. 4, the normalized surface density $\rho$ of the colloid particles is calculated for $\phi=0^{\circ}$ with various values of $\theta$ and with the parameters listed in Table 1 by the previous theory [5]. For $\phi=180^{\circ}$, the calculation is the same as for $\phi=0^{\circ}$. As seen in Fig.4, values of $\rho$ is symmetric with respect to $\mathrm{x} / \mathrm{b}$ $=1$ (the magnetic transition point) only when $\theta=90^{\circ}$, which agrees well with the experimental value. In Fig. 4, the peak values of $\rho$ at $\mathrm{x} / \mathrm{b}=1$ is far larger than those at $\mathrm{x} / \mathrm{b}=0$ and 2 when $\theta>30^{\circ}$, and this suggests that the magnetic transition lines are alternately dark in the Bitter patterns. Actually wide or dark lines are alternately observed in Fig. 2 (a) and (b), and also in Fig.3(b) $\sim$ (f).

\section{$1.0 \mathrm{kFCI}$ Recording}

The Bitter patterns of the $1.0 \mathrm{kFCI}$ recording are observed in the same way as in the $0.5 \mathrm{kFCI}$ recording. First, patterns for $\mathrm{H}_{\mathrm{ex}}=200$ Oe at $\theta=90^{\circ}$ and at $\theta=270^{\circ}$ are shown on the same area of the sample by the wet Bitter method in Fig.5 (a) and (b), respectively. In each pattern, any difference of the colloid density is not observed between neighboring bits. Furthermore, it is clear that the magnetic transition lines are alternately dark and wide in Figs. 5 (a) $\left(\mathrm{H}_{\text {ox }}\right.$

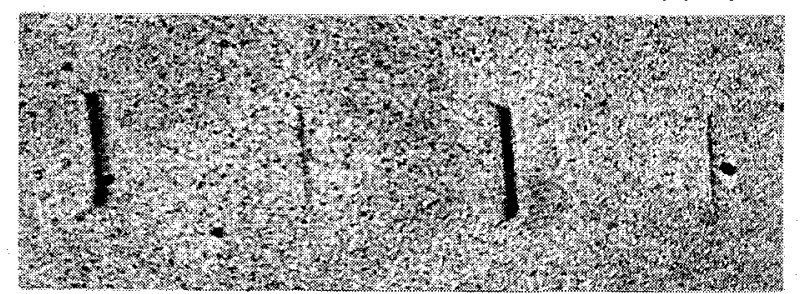

(a) $\mathrm{H}_{\mathrm{ex}}=200 \mathrm{Oe}\left(\theta=90^{\circ}\right)$

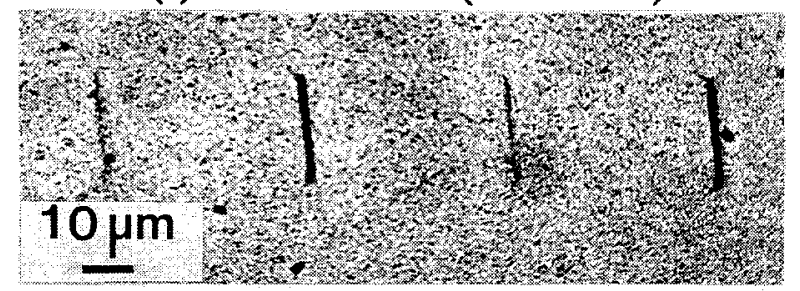

(b) $\mathrm{H}_{\mathrm{ex}}=200 \mathrm{Oe}\left(\theta=270^{\circ}\right)$

Fig. 2 Bitter patterns of $0.5 \mathrm{kFCl}$ recording on the same area of the sample. 


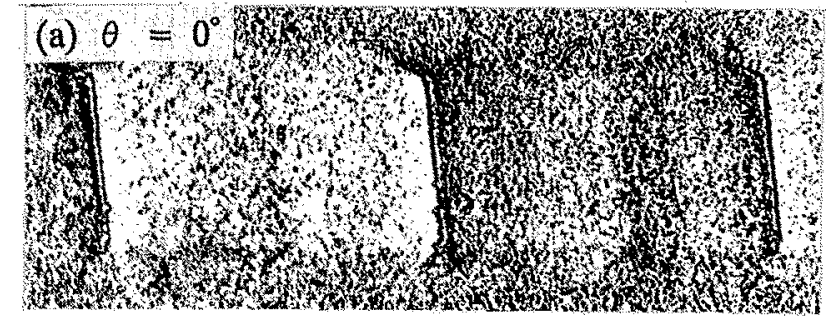

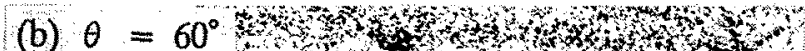
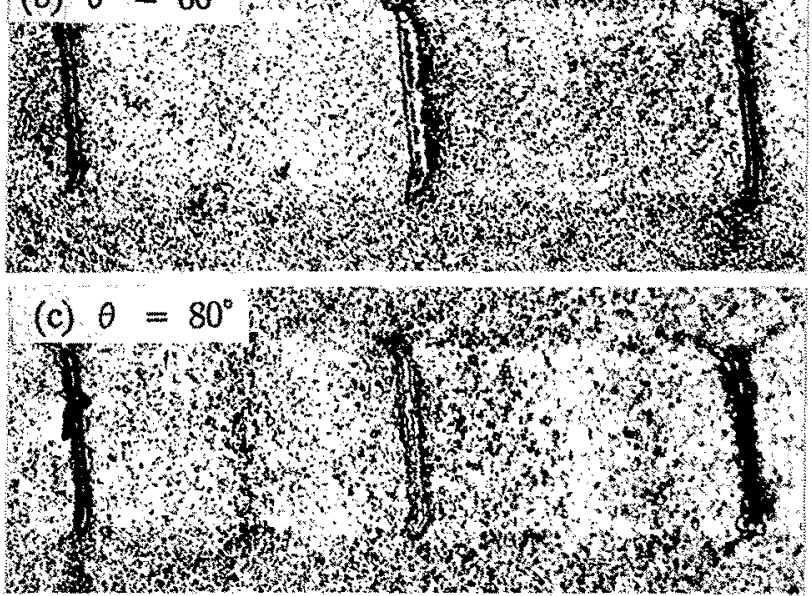

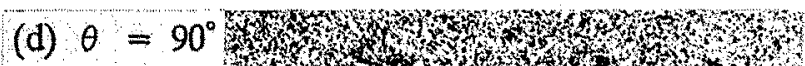

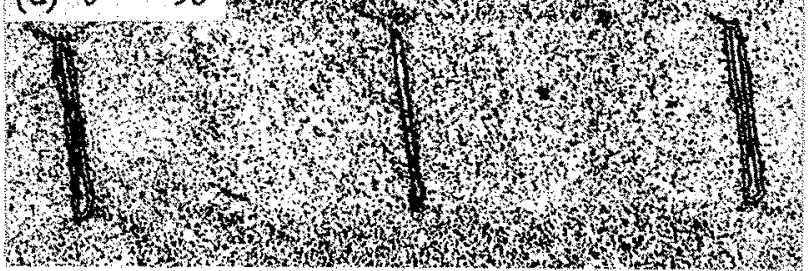
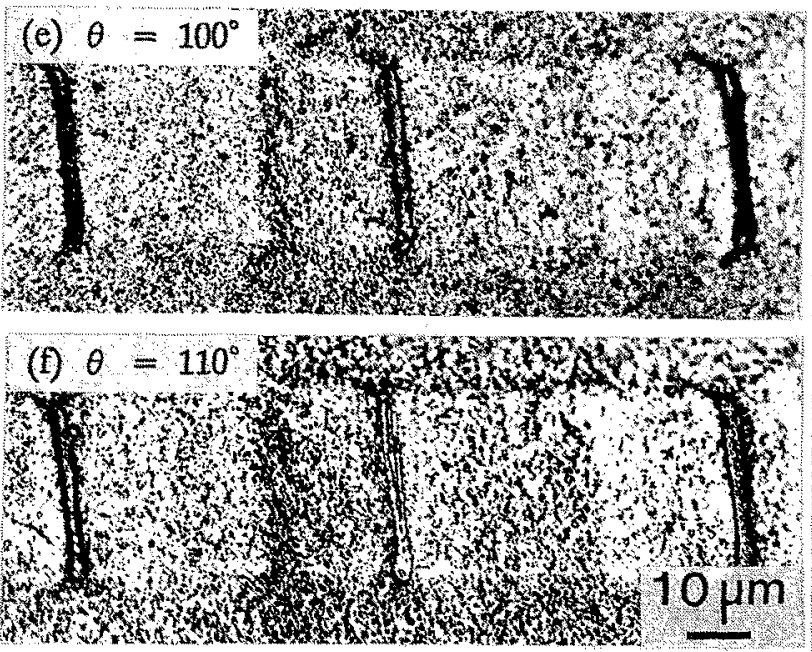

Fig. 3 Bitter patterns of $0.5 \mathrm{kFCI}$ recording in $\mathrm{H}_{\mathrm{ex}}=200 \mathrm{Oe}$.

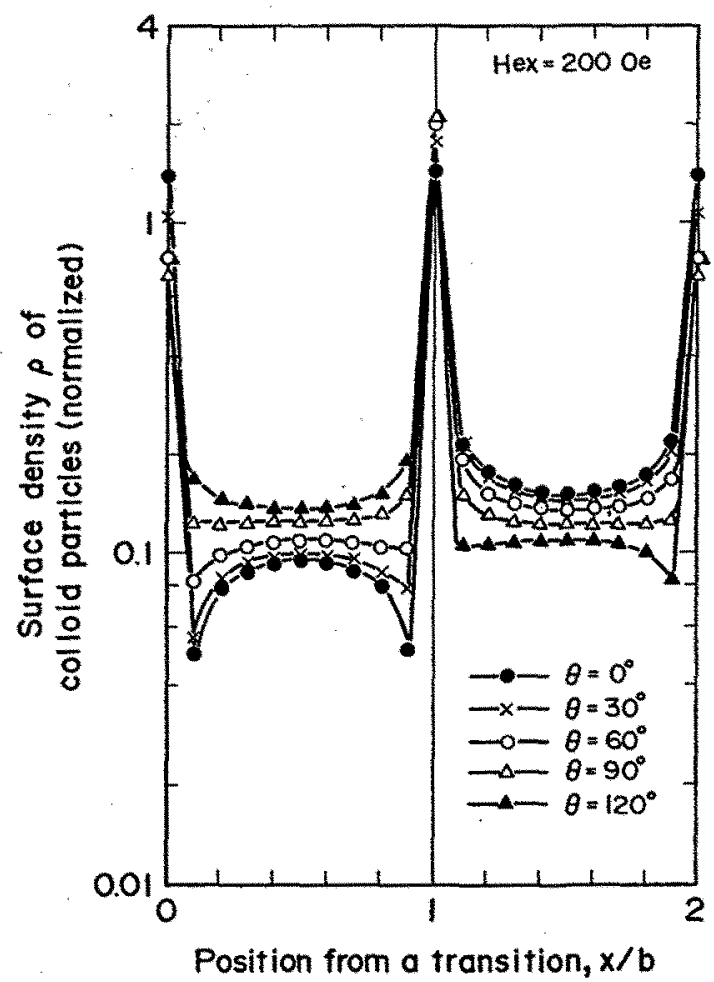

Fig. 4 Calculated surface density of colloid particles in $\mathrm{H}_{\mathrm{bx}}=200 \mathrm{Oe}$ for $0.5 \mathrm{kFCI}$ recording when the inclination angle $\phi=0^{\circ}$.

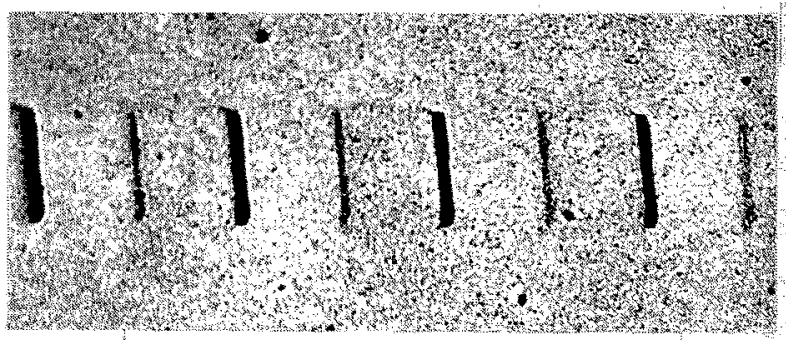

(a) $\mathrm{H}_{s x}=200 \mathrm{Oe}\left(\theta=90^{\circ}\right)$

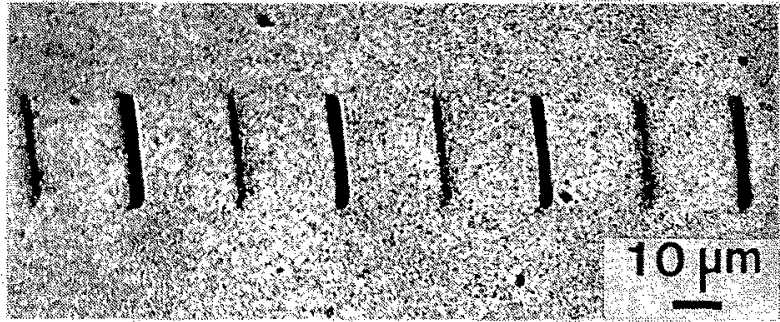

(b) $\mathrm{H}_{\mathrm{ox}}=200 \mathrm{Oe}\left(\theta=270^{\circ}\right)$

Fig. 5 Bitter patterns of $1.0 \mathrm{kFCI}$ recording on the same area of the sample. 
$=200 \mathrm{Oe}, \theta=90^{\circ}$ ) and $5(\mathrm{~b}) \mathrm{H}_{\mathrm{ox}}=200 \mathrm{Oe}$, $\theta=270^{\circ}$ ), as seen in Fig.2(a) and (b) of the $0.5 \mathrm{kFCI}$. This alternate appearance of the dark transition line is caused by the same reason as in the $0.5 \mathrm{kFCI}$ recording described above, and values of $\rho$ will be shown later (in Fig. 7). Figure 6 shows changes of the colloid density in neighboring bits with $\mathrm{H}_{\mathrm{ox}}=200 \mathrm{Oe}$ for various $\theta$. The contrast between light and dark bits at $\theta=0^{\circ}$ decreases with the increase of $\theta$ (Fig. 6 (a) $\sim(\mathrm{c})$ ), and it nearly disappears at $\theta=90^{\circ}$ ((d)). For $\theta>90^{\circ}$, the contrast of the pattern appears again ((e) and (f)). Including the result in Fig. 5 (a) and (b), we obtain $\theta$ $=90^{\circ}$ and $270^{\circ}$ for the equal density between neighboring bits. Therefore, equation (1) gives the same result, $\phi=0^{\circ}$ and $180^{\circ}$, as in the $0.5 \mathrm{kFCI}$ recording.

Figure 7 shows the surface density $\rho$ calculated in the same way as in Fig.4 for $\phi=0^{\circ}$ by the theory [5]. In this figure, $\rho$ is symmetric with respect to $\mathrm{x} / \mathrm{b}=1$ only for $\theta=90^{\circ}$, which agrees with the above result of the observation. It is also evident in Fig.7 that the degree of the asymmetry of $\rho$ as to $\mathrm{x} / \mathrm{b}=1$ increases when $\theta$ becomes far from $90^{\circ}$, and such a tendency is observed in Fig.6. In Fig. 7, peak values of $\rho$ at $x / b=1$ are larger than those at $\mathrm{x} / \mathrm{b}=0$ and 2 for $\theta>$ $30^{\circ}$. This result is the same as shown in Fig. 4 for the $0.5 \mathrm{kFCl}$, and in accord with this result, dark or wide transition lines are alternately observed in Fig.5 (a), (b) and in Fig. 6 (b) $\sim$ (f).
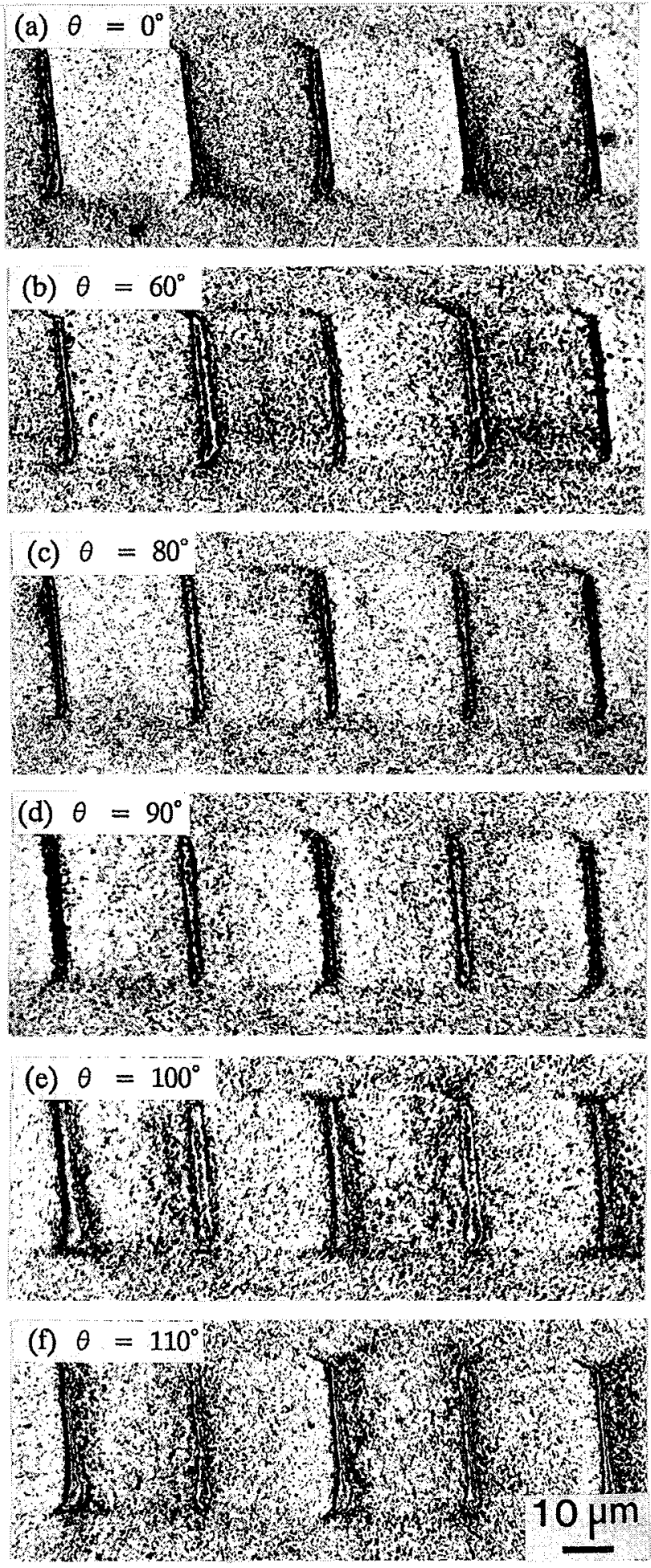

Fig. 6 Bitter patterns of $1.0 \mathrm{kFCI}$ recording in $\mathrm{H}_{\mathrm{ox}}=200 \mathrm{Oe}$. 


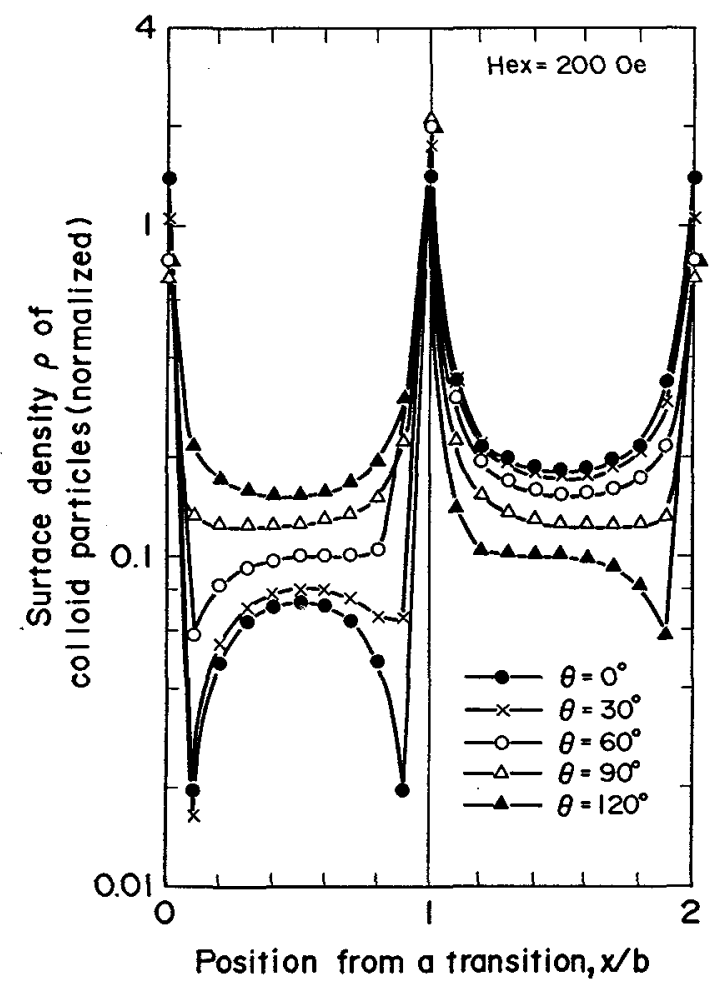

Fig. 7 Calculated surface density of colloid particles in $\mathrm{H}_{\mathrm{ax}}=200 \mathrm{Oe}$ for $1.0 \mathrm{kFCI}$ recording when the inclination angle $\phi=0^{\circ}$.

\section{CONCLUSIONS}

A modified Bitter pattern technique was applied to evaluate the direction of longitudinally recorded magnetization in the VTR tape made of acicular iron particles.

(1) The inclination angle $\phi$ of the recorded magnetization was found to be $0^{\circ}$ and $180^{\circ}$ for both 0.5 and $1.0 \mathrm{kFCI}$ recordings by using the result of the theory [5].

(2) Changes of the pattern contrast with the angle of magnetic field agreed nearly with the calculation for the $1.0 \mathrm{kFCI}$ recording.

(3) Magnetic transition lines appeared alternately dark or wide when $\theta>30^{\circ}$ in both 0.5 and 1.0 $\mathrm{kFCI}$ recordings, and this fact agreed well with the calculation of colloid density on the tape.

The authors would like to thank Dr. M. Kishimoto of Hitachi Maxell, Ltd. for his helpful discussions.

\section{REFERRENCES}

[1] K.Goto, T.Sakurai and O.Kitakami: Jpn. J. Appl.Phys. 25(1986)1358.

[2] K.Goto and T.Sakurai: Appl. Phys. Lett. 20(1977)335.

[3] U.Hartmann: J. Mag. Magn. Mat. 68(1987) 298.

[4] H.Nishida and K.Osano: IECE Technical Report MR87-44 (1987)31 (in Japanese).

[5] O.Kitakami: Jpn. J. Appl. Phys. 30(1991) L739.

[6] T.Sakurai, O.Kitakami and K.Goto: Jpn. J. Appl. Phys. 30(1991)L1279.

[7] T.Sakurai, K.Goto and T.Inoue: J. Jpn. Inst. Met. 51(1987)774 (in Japanese). 